the false image. The surgeon measures by means of the string the distance between the arrow and the patient's finger. This obviates dependence on a sometimes dull patient's assessment. The inch spaced pieces of metal enable this to be done in the dark.

(2) The degree of tilting of the false image can be found by tilting the handle of the lamp until the false image is erect and then noticing by touch the angle between the handle and the dependant string.

This device has been used for some time and has been found useful. It is simple and has the advantage of always being at hand in that it is not "another instrument" but a simple fitting that can always be carried about in the ophthalmoscope case. It has been of particular help in the examination of bedded patients, especially those unable to sit up.

Méssrs. Theodore Hamblin intend making this device an accessory to their Lister-Morton Ophthalmoscope as soon as the pressure of war work permits.

I wish to thank Capt. C. J. King, R.E.M.E., Officer Commanding Surgical Equipment Workshop, R.E.M.E., for his kind co-operation in making the instrument.

This report is made with the permission of Colonel W. B. Stevenson, R.A.M.C., Officer Commanding a General Hospital.

\title{
SUBCUTANEOUS SPLITTING OF THE LID IN THE OPERATIVE TREATMENT OF SENILE ECTROPION*
}

\author{
BY \\ H. LytTon \\ LONDON
}

THE bugbear of the marginal splitting of the lid in the KuhntSzymanowski operation is the late development of trichiasis as the marginal scar tends to pull the canals of the lashes inwards. Another drawback is the frequency of the cutting through of tarsal sutures.

The following method avoids the splitting of the lid margin, while giving sufficient control of the extent to which the lid margin is inverted.

The skin-muscular layer of the lid is separated from the tarsoconjunctival layer by subcutaneous splitting from the incision $\mathrm{AB}$ at the outer canthus (Diagram 1).

The splitting of the lid is best done by an angular pair of scissors, and should be extended up immediately underneath the lid margin keeping close to the anterior surface of the tarsus. 


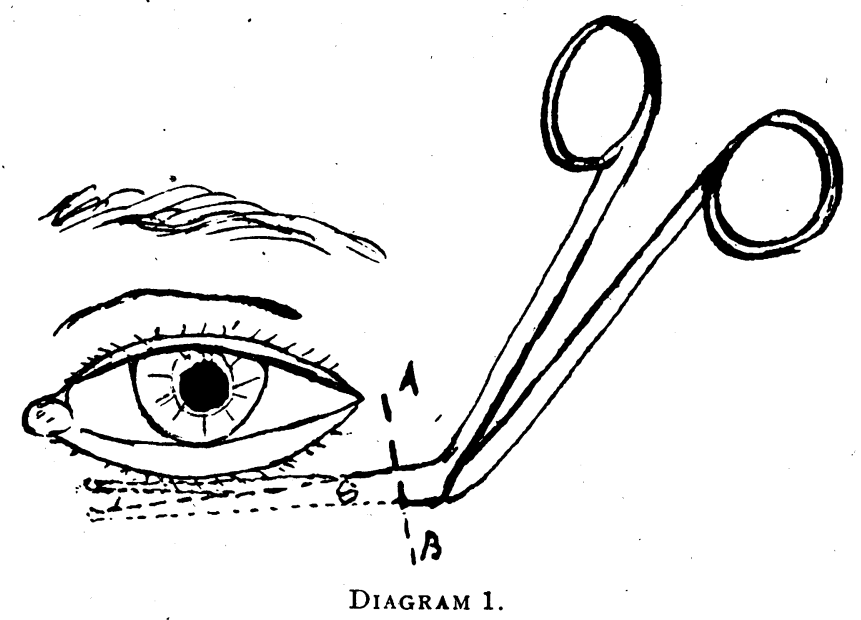

Subcutaneous splitting of the lid.

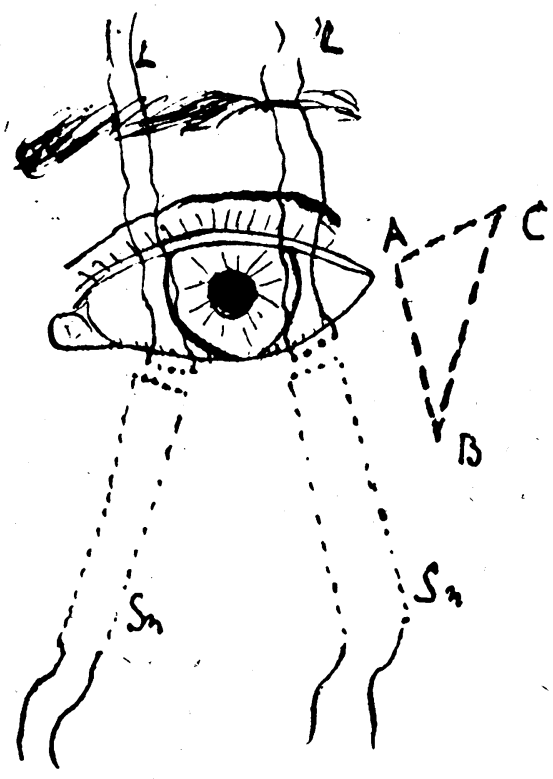

DIAGRAM 2.

Insertions of sutures. Completion of the incision $A B$ to the Szymanowski triangle ABC.

Two mattress sutures LL (Diagram 2) are inserted in the anterior layer of the lid near the lid margin. These sutures are used to lift the skin. The tarsal plate is drawn down and in by two Snellen's sutures $\mathrm{SnSn}$. The lateral incision $\mathrm{AB}$ is completed to the excision of the Szymanowski triangle ABC. 
In the last stage of the operation (Diagram 3) the Snellen's sutures are tied in the usual way over a small piece of rubber, the lifting sutures are fastened above the eyebrow by two strips of adhesive plaster, and the triangular skin excision is sutured. The lateral sutures are removed on the fifth day, the Snellen's and lifting

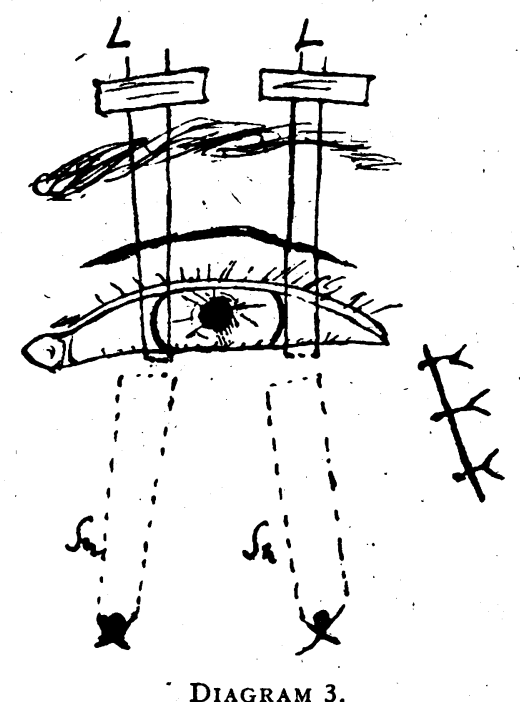

Skin lifted by the marginal sutures $L L$. Tarsus drawn down by the Snellen sutures Sn Sn.- Szymanowski excision sutured.

sutures are left three or four days longer to make sure that the tarsus has become attached to the skin-muscular layer at a lower level. The lid lifting sutures should not be allowed to cut through. If they are likely to 'do so, they have to be removed. This inconvenience may be avoided by not pulling the threads too taut when fastening them to the skin of the forehead.

\section{ANNOTATION}

\section{Fees}

From the ophthalmological point of view a fee is a reward for professional services and we need not consider the meaning of the word with regard to feudal land tenure, or that of a tribute to a superior. It is of interest to note that the shorter Oxford Dictionary gives, amongst other meanings, "payment to a public officer (? orig. one who held his office in fee) for the execution of his functions, 